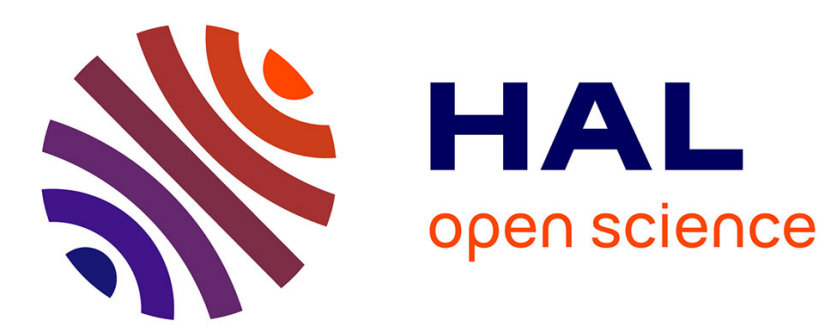

\title{
Low space order analysis of radial pressure in SPMSM with analytical and convolution approaches
}

\author{
Patricio La Delfa, Mathias Fakam, Michel Hecquet, Frédéric Gillon
}

\section{To cite this version:}

Patricio La Delfa, Mathias Fakam, Michel Hecquet, Frédéric Gillon. Low space order analysis of radial pressure in SPMSM with analytical and convolution approaches. IEEE Transactions on Magnetics, 2016. hal-01711040

\author{
HAL Id: hal-01711040 \\ https://hal.science/hal-01711040
}

Submitted on 16 Feb 2018

HAL is a multi-disciplinary open access archive for the deposit and dissemination of scientific research documents, whether they are published or not. The documents may come from teaching and research institutions in France or abroad, or from public or private research centers.
L'archive ouverte pluridisciplinaire HAL, est destinée au dépôt et à la diffusion de documents scientifiques de niveau recherche, publiés ou non, émanant des établissements d'enseignement et de recherche français ou étrangers, des laboratoires publics ou privés. 


\title{
Low space order analysis of radial pressure in SPMSM with analytical and convolution approaches.
}

\author{
Patricio La Delfa, Mathias Fakam, Michel Hecquet, Fréderic Gillon. \\ Laboratory of Electrical Engineering and Power Electronics, L2EP, Ecole Centrale de Lille, \\ Cité scientifique, CS20048, 59651 Villeneuve d'Ascq Cedex-France.
}

\begin{abstract}
This paper presents an analysis of low the space order of the air-gap radial Maxwell pressures in Surface Permanent Magnet Synchronous Machines (SPMSM) with fractional slot concentrated windings. The air-gap Maxwell pressures result from the multiplication of the flux density harmonics due to magnetomotive forces and permeance linked to the magnet, the armature, and the stator slots and their interactions. One low space order is selected and different approaches are compared to determine the origin of this pressure. First, an analytical prediction tool ACHFO (Analytical Calculation of Harmonic Force Orders) is issues to calculate the space and time orders of these magnetic pressure harmonics while identifying their origin in terms of interactions between magnet, armature and teeth effects. Additionally, the analytical prediction of ACHFO is compared with the flux density convolution and finite element approaches. The main advantage of our tool is the speed of computation. Finally, an experimental Operational Deflection Shape measurement (ODS) is performed to show the deflection shape of the low space order selected.
\end{abstract}

Keywords - fractional slot concentrated winding, air-gap radial Maxwell pressures; lowest space order; analytical tool; convolution analysis; operational deflection shape (ODS).

\section{INTRODUCTION}

The commitment of many countries to reduce greenhouse gas emissions and preserve primary energy resources has significantly contributed to the development of hybrid and electric transport. The use of concentrated winding permanent magnet synchronous machines in transport applications in which speed variation is required increases efficiency and power density. It is essential to take into account both the electrical characteristics designing electrical machines and the electromagnetic acoustic noise radiated. This source of audible noise arises when Maxwell pressures induce dynamic deflections of the external structure (stator or rotor), which then propagate in the ambient air as acoustic waves [1], [2].

One goal of this research is to identify and analyse the low space order of the air-gap radial pressure (Maxwell pressure), i.e. the harmonics specific to the magnets, the armature, and the teeth and their interactions which we call specific effects. Many references provide analytical relations in order to evaluate radial pressures. Each harmonic of this radial pressure is well-known [2], [3], [5], [11], for example, coupled with the interaction between the slotting and the magnetomotive force (MMF), or the saturation effect [4], [6].

On the other hand, the contribution of each air-gap flux density $\mathrm{B}\left(\mathrm{t}, \alpha^{\mathrm{s}}\right)$ harmonic to identify the origin of each harmonic radial pressure is not easy. Also the origin of each radial pressure harmonic component is required. Indeed many contributions of specific effects linking the interactions between armature, rotor and permeance effects are combined. In [7] and [8] the author gives different contributions for each harmonic of the pressure but without a slotting effect, in the case of synchronous machines with magnets (IPM and SPM).

Analytical models (permeance / magnetomotive force and winding function approaches) [3], [5], semianalytical subdomain models [9] and the finite element method can be used to evaluate the airgap flux density. The latter two approaches are precise and it is possible to deduce the tangential and radial components of flux density.

In this paper, only the origin of the radial pressure is investigated. Our approach is described and illustrated on a Surface Permanent Magnet Synchronous Machine (SPMSM) with fractional slot concentrated windings. A tool named ACHFO (Analytical Calculation of Harmonic Force Orders) is applied to predetermine and identify all the sources of the radial pressure only for the low space orders established by specific effects, the interaction effects mentioned previously, and their own carrier frequencies. The ACHFO tool does not use airgap flux density but only the harmonics of permeance, rotor and stator MMF and their interactions. At last, ACHFO cannot determine the amplitude and the phase of space orders [10]. Although the tool gives a complete picture of each harmonic of the radial pressure versus time and space orders, some of them have no influence on the magnetic noise [11], [12], [13].

In order to validate the origin of the radial pressure, different approaches are compared such as the convolution approach [14]. In addition, an experimental Operational Deflection Shape measurement (ODS) is performed to show the deflection shape of the low space order. 


\section{SCOPE OF THE WORK}

\section{A. Description of the machine studied}

The structure is presented in figure 1, a modular machine defined by $2 p=Z_{s} \pm 2$, ( $Z s$ number of slots fixed to $Z_{s}=12$, pole pair number $p=5$ ).



Fig. 1: SPMPM Machine and flux lines by FEM.

What is more, this machine is characterized by a winding factor $\mathrm{k}_{\mathrm{w}}(1)=0.933, \mathrm{~S}_{\mathrm{pp}}=0.4$, Least Common Multiple $(\mathrm{lcm})=60$, and Geatest Common Divider $(\mathrm{gcd})$ $=2$. The winding factor $K_{w}$ and the number of slots per pole per phase $S_{p p}$ are given in [15]. It also gives the $l \mathrm{~cm}$ and the $g c d$ described as used in [11], [16]. The slot-pole combination is important in terms of vibration generation as shown in [8], [13], [17]. The gcd, between the number of slots and pole pair number, corresponds to the lowest dominant non-zero of the magnetic radial pressure harmonics.

A tooth concentrated winding SPMSM is chosen for its high power density and high efficiency although it makes it harder to obtain a high slot fill factor, since there are two layers per slot. The winding pattern is designed using a star of slots methodology [18], and the author [19] analyse the windings configuration on fractional-slots PMSM performance.

The star of slots consists in installing and connecting the elementary windings to conform to the phases shift between the three phases of the supply and guarantee maximal electromagnetic torque.



Fig.2: Phase 1 (4 coils around T1, T2, T7 and T8)
Phase 1 shown in figure 2 illustrates the elementary windings installed on teeth $\mathrm{T} 1, \mathrm{~T} 2$ and diametrically opposed teeth T7, T8. Both real and imaginary elementary fundament electromotive forces (EMF) are equal to 1 and the resulting phase $1 \mathrm{EMF}$ is shown in figure 3 .

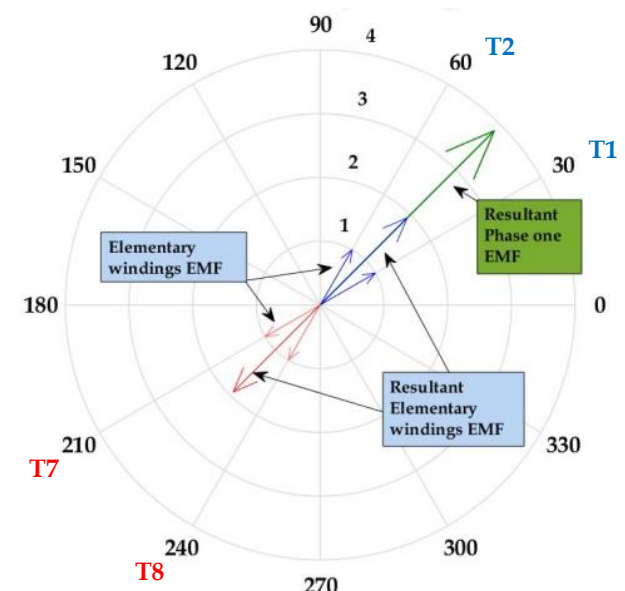

Fig. 3: Phase 1 (Elementary winding and resultant EMF)

First, we present all the harmonics of the radial pressures of this machine through a 2D finite element calculation. This calculation will be the reference and the lowest order will be selected for a discussion of these origins by regarding the different approaches to be compared. The aim is to select a fast and effective approach to optimize the structure.

\section{FINITE ELEMENT SIMULATIONS}

The finite element simulations include the rotational movement of the machine and the coupling with the circuit, (i.e. phase resistor, synchronous inductance and inductance head winding). The power supply is sinusoidal.

\section{A. Air-gap radial flux density}

The FE electromagnetic model determines the distribution in time and space of the radial air-gap flux density $\mathrm{B}\left(\mathrm{t}, \alpha^{\mathrm{s}}\right)$ with $\alpha^{\mathrm{s}}$ being the stator mechanical angle.

We defined a line in the centre of air-gap for each time value (200 points per period). It determines the flux density $\mathrm{B}\left(\alpha^{\mathrm{s}}\right)$ : 360 points divided by $2 \pi$.

According to (1), it also determines $\mathrm{B}_{\mathrm{aR}}\left(\mathrm{t}, \alpha^{\mathrm{s}}\right)$ and $\mathrm{B}_{\mathrm{pm}}\left(\mathrm{t}, \alpha^{\mathrm{s}}\right)$, the armature and magnet radial flux density, respectively [2]. Note the flux density $B_{a R}$ is obtained by considering the magnet flux density as equal to zero and the magnet relative permeability is retained. In this study only the radial components is taken into to account. Indeed, [20] shows that radial and tangential flux densities have the same orders and frequencies.

$$
\begin{aligned}
& B\left(t, \alpha^{s}\right)=B_{a R}\left(t, \alpha^{s}\right)+B_{p m}\left(t, \alpha^{s}\right) \\
& B_{a R}\left(t, \alpha^{s}\right)=\sum\left(B_{v} \cos \left(v p \alpha^{s} \pm k \omega t\right)\right) \\
& B_{p m}\left(t, \alpha^{s}\right)=\sum\left(B_{\mu} \cos \left(\mu p \alpha^{s} \pm k \omega t+\phi_{\mu}\right)\right)
\end{aligned}
$$

$v, \mu$ : armature and permanent magnet space orders $\phi_{\mu}$ : Both angle rotor /stator for same order considered [rad]. 


\section{B. Air-gap Radial pressure.}

On the base of the air-gap radial flux density versus time and space, the air-gap radial Maxwell pressure $\sigma\left(\mathrm{t}, \alpha^{\mathrm{s}}\right)$ can be approximated by relation (4).

$$
\sigma\left(t, \alpha^{s}\right) \simeq\left\{B\left(t, \alpha^{s}\right)\right\}^{2} /\left(2 \mu_{0}\right)
$$

The global air-gap radial pressure shown in figures 4(a-b),versus space and time, estimated from the global air gap flux density reveal large number of harmonics. Figure 4(c-d) shows only the armature radial pressure and figure 4(e-f), only the magnet radial pressure. Note the different FFT give absolute values for the magnitudes.
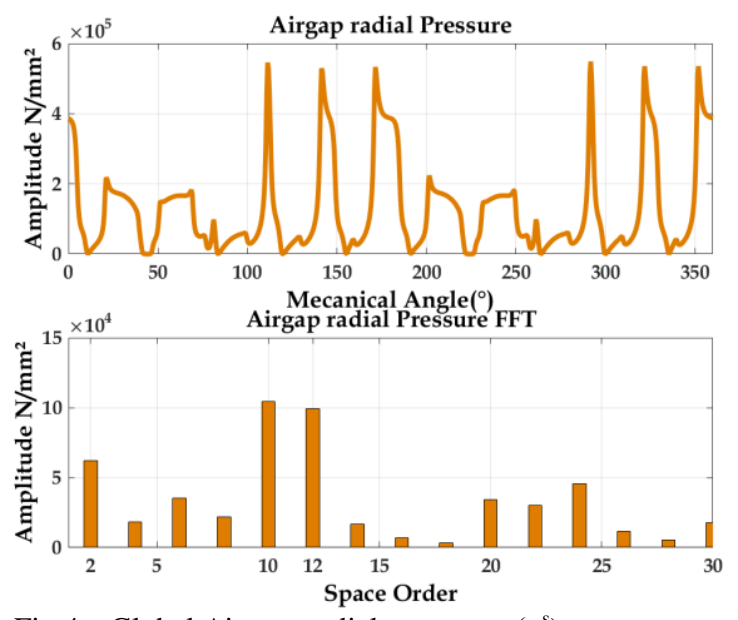

Fig.4a: Global Air-gap radial pressure $\sigma\left(\alpha^{\mathrm{s}}\right)$ versus space
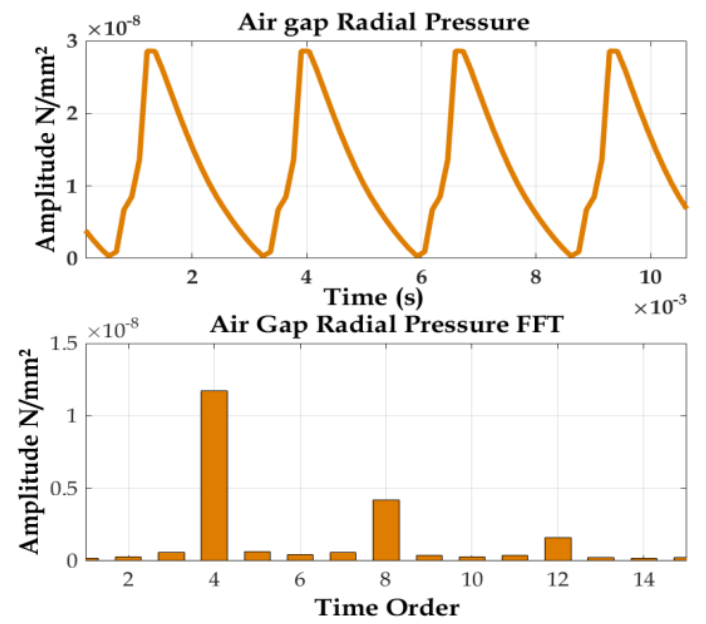

Fig.4b: Global air-gap radial pressure $\sigma(\mathrm{t})$ versus time

We obtain harmonics $\mathrm{H}_{10}, \mathrm{H}_{12}$ which represent $2 \mathrm{p}$ poles and the number of slots $Z_{s}$, respectively. Low orders $\mathrm{H}_{2}$ and $\mathrm{H}_{4}$ are also shown.
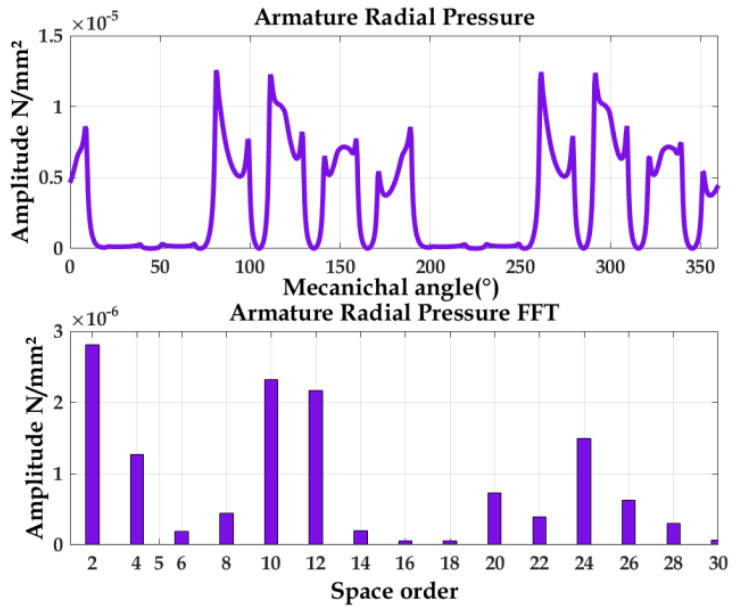

Fig.4c: Armature radial pressure $\sigma_{\mathrm{aR}}\left(\alpha^{\mathrm{s}}\right)$ versus space


Fig.4d: Armature radial pressure $\sigma_{\mathrm{aR}}(\mathrm{t})$ versus time
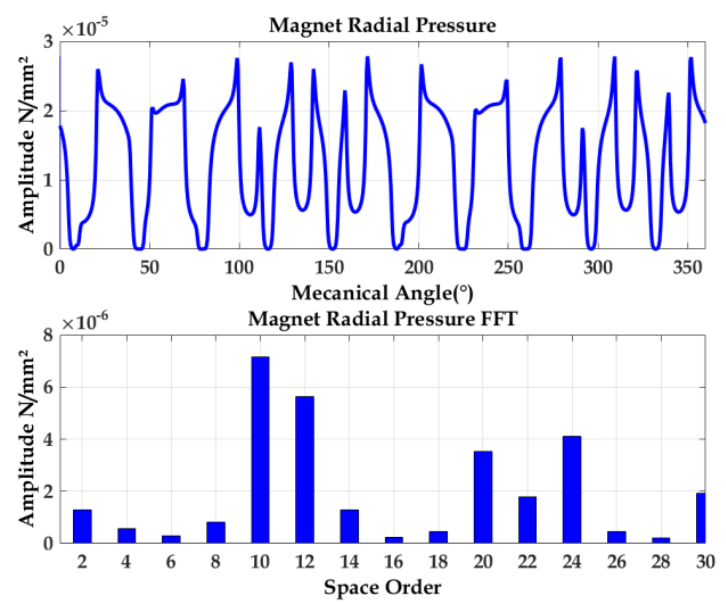

Fig.4e: Armature radial pressure $\sigma_{\mathrm{pm}}\left(\alpha^{\mathrm{s}}\right)$ versus space 

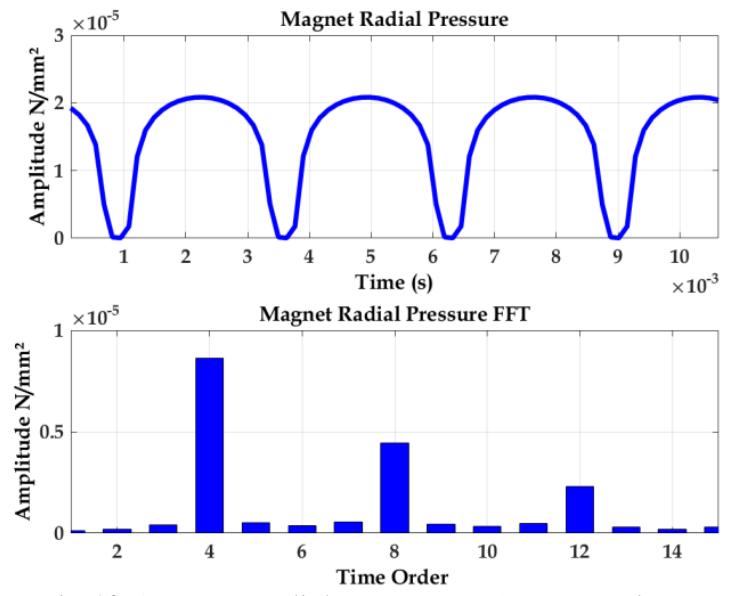

Fig.4f: Armature radial pressure $\sigma_{\mathrm{pm}}(\mathrm{t})$ versus time.

Figure 5 depicts the lowest space orders of the global air-gap radial pressure FFT 2D versus time and space for the nominal working point. A space order 2 at $2 \mathrm{fs}$ is shown, noted $(2,2 \mathrm{fs})$. Also shown are negative pressure rays at $(-2,4 \mathrm{fs}),(-4,2 \mathrm{fs})$ and positive rays at $(4$, $4 \mathrm{fs}$ ) which produce opposing revolving vibratory waves.

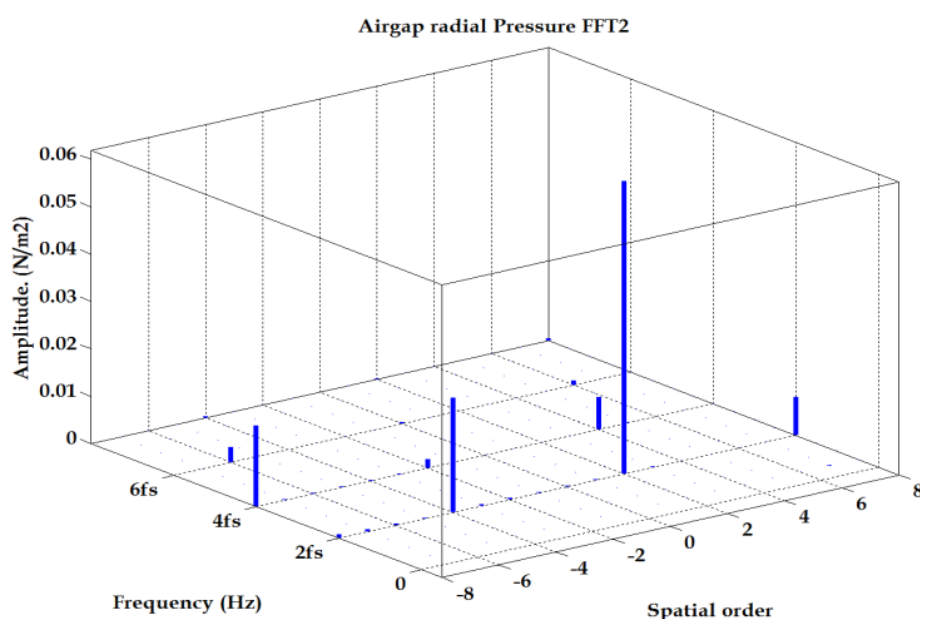

Fig. 5: FFT 2D of the air-gap radial pressure (global case)

The modular machine studied gives the $g c d=2$, which corresponds to the dominant lowest non-zero pressure order 2 found in simulations. The previous figure illustrates the higher order 2 at $2 \mathrm{fs}$ magnitude.

\section{ORIGIN OF RADIAL AIR-GAP PRESSURE}

The objective of this section is to understand the origin of a pressure line for the lowest space order. In electrical machines, it can be linked to many effects and their combination (teeth, stator and rotor field, etc). The origin of about order 2 to $2 \mathrm{fs}$ determined by different approaches will be compared. Initially, Matlab tool that incorporates all the harmonics of the radial pressure is developed. The interest of this is that it determines each pressure line produced quickly.

\section{A. Analytical Calculation of Force Orders (ACHFO)}

The ACHFO tool disregards eccentricity, and considers a smooth rotor link to the surface permanent magnet machine. It identifies all the space orders and frequencies of the air-gap Maxwell pressure harmonics in a given electrical machine. It also tracks the origin of the lowest space orders, i.e. combined interactions between the armature, magnets and slotting effects, and its own interactions too. In relation (5), the flux density is calculated by the product ofthe air-gap permeance per unit of surface by the magnetomotive forces for the rotor (magnet) and the stator (concentrated winding).

Note in (6), $A_{\xi}$ represents the $\xi_{\text {th }}$ slotting permeance per unit [3]. The air-gap permeance is linked versus space only, the rotor is smooth [20].

$$
\sigma\left(t, \alpha^{s}\right) \simeq 1 / 2 \mu_{0} *\left\{\Lambda\left(\alpha^{s}\right) *\left[F_{r}\left(t, \alpha^{s}\right)+F_{s}\left(t, \alpha^{s}\right)\right]\right\}^{2}
$$

With :

$$
\begin{aligned}
\Lambda\left(\alpha^{s}\right)=\Lambda_{0} / 2+\left(\mu_{0} / e\right) k_{c} \sum_{(\xi)} A_{\xi} \cos \left(\xi Z_{s} \alpha^{s}\right) \\
\xi_{\text {th }}=\{0,1,3,5, \ldots\}
\end{aligned}
$$

$$
F_{r}\left(t, \alpha^{s}\right)=\sum_{(k)} f_{m \mu} \cos \left(\mu p \alpha^{s} \pm \omega t+\phi_{\mu}\right)
$$$$
\mu_{\mathrm{th}}=\{1,3,5, \ldots\}
$$

$$
F_{s}\left(t, \alpha^{s}\right)=\sum_{(k)} f_{m v} \cos \left(v p \alpha^{s} \pm \omega t\right)
$$

$$
\begin{aligned}
\sigma\left(t, \alpha^{s}\right) \simeq & 1 / 2 \mu_{0} * \Lambda\left(\alpha^{s}\right)^{2 *} F_{r}\left(t, \alpha^{s}\right)^{2}+1 / 2 \mu_{0} * \Lambda\left(\alpha^{s}\right)^{2 *} F_{s}\left(t, \alpha^{s}\right)^{2} \\
& +1 / \mu_{0} * \Lambda\left(\alpha^{s}\right)^{2 *} F_{r}\left(t, \alpha^{s}\right)^{*} F_{s}\left(t, \alpha^{s}\right) .
\end{aligned}
$$

$v, \mu, \xi$ : Space order armature/permanent magnet/permeance

Consequently, we can obtain the relationship (9) that reveals three families of space classified into three groups:

-the first one represents the multiplication of several air-gap permeance waves by several rotor magnetomotive force waves only $\left(\mathrm{F}_{\mathrm{r}}\right)$.

-the second one represents the multiplication of several air-gap permeance waves by several stator magnetomotive force waves only $\left(\mathrm{F}_{\mathrm{s}}\right)$.

-the third one represents the multiplication of several air-gap permeance waves by both $\mathrm{F}_{\mathrm{r}}$ and $\mathrm{F}_{\mathrm{s}}$ waves.

Table 1 summarizes the analytical formulations used by the ACHFO tool. Note that the ACHFO analytical tool does not take into account the magnitude of the pressure waves. The tool gives the origin of the harmonics $(2,2 \mathrm{fs})$ in Table 2.

To conclude this part, the air-gap pressure low order 2 at $2 \mathrm{fs}$ represents the total effects given by ACHFO, i.e. linked armature order, magnets-permeance, magnetsarmature and magnet-permeance-armature interactions. Analysis of table 2 reveals that the order $(2,2 \mathrm{fs})$ does not result only from magnet-armature interaction, which means that it also has a load origin. 
TABle 1: Pressure HaRMONICS

\begin{tabular}{|c|c|c|}
\hline Effect/ Group & Order radial pressure: & Frequency: \\
\hline $\begin{array}{l}\text { Due to magnets : } \\
\text { Own interaction : }\end{array}$ & $\begin{array}{l}2 \mu_{\mathrm{th}} \mathrm{p} \\
\text { and } \mu_{\mathrm{th}}=\{1,3,5,7 \ldots\}=(2 \mathrm{k}+1) \\
\left(\mu_{1} \pm \mu_{\mathrm{th}}\right) \mathrm{p} ; \mu_{1}=1\end{array}$ & $\begin{array}{l}2 \mathrm{fs}(1+2 \mathrm{k}) \\
\mathrm{k}=\{0,1,2, \ldots\} \\
\left(\mu_{1} \pm \mu_{\mathrm{th}}\right) . \mathrm{fs}\end{array}$ \\
\hline $\begin{array}{l}\text { Due to armature : } \\
\text { Own interaction : }\end{array}$ & $\begin{array}{ll}2 v_{\text {th }} ; & v_{\text {th }}=6 \mathrm{k} \pm 1 \\
\left(v_{1} \pm v_{\text {th }}\right) & k=\{0,1,2 . .\}\end{array}$ & $\begin{array}{l}2 \mathrm{fs} \\
2 \mathrm{fs}\end{array}$ \\
\hline \multicolumn{3}{|c|}{ Interactions due to } \\
\hline Magnet and permeance: & $\begin{array}{l}2\left(\mu_{\text {th }} \pm \mu_{\text {th }} Z_{\mathrm{s}}\right), \mu_{\text {th }}=\{1,3,5,7 . .\} \\
\left(\mu_{\text {th } 1} \pm \mu_{\text {th }}\right) \mathrm{p} \pm\left(\xi_{2} \pm \xi_{1}\right) Z_{\mathrm{s}} \\
\left(\mu_{\text {th }} \pm \mu_{\text {th }}\right) \cdot \mathrm{p} \pm \xi . Z_{\mathrm{s}} \\
\xi=\{0,1,3,5 \ldots\}\end{array}$ & $\begin{array}{l}2 \mu_{\mathrm{th}} \text { fs } \\
2 \mathrm{fs}\left(\mu_{\mathrm{th} 1} \pm \mu_{\mathrm{th}}\right) \\
\left(\mu_{\mathrm{th}} \pm \mu_{\mathrm{th}}\right) . \mathrm{f}_{\mathrm{s}}\end{array}$ \\
\hline Armature-Magnets: & $\left(\mu_{\mathrm{th}} \cdot \mathrm{p}\right) \pm v_{\mathrm{th}}$ & $\left(\mu_{\mathrm{th}} \pm 1\right) . \mathrm{f}_{\mathrm{s}}$ \\
\hline $\begin{array}{l}\text { Magnets- Permeance- } \\
\text { Armature-: }\end{array}$ & $\left(\mathrm{p} . \mu_{\mathrm{th}}\right) \pm\left(\xi . Z_{\mathrm{s}}\right) \pm v_{\mathrm{th}}$ & $\left(\mu_{\mathrm{th}} \pm 1\right) \cdot \mathrm{f}_{\mathrm{s}}$ \\
\hline
\end{tabular}

TABLE 2: ANALYTICAL ORDERS PRESSURE RESULTS Orders \pm 2 at $2 f s$

\begin{tabular}{|c|c|}
\hline \multicolumn{2}{|c|}{ Orders \pm 2 at $2 f s$} \\
\hline & Harmonics H due to: \\
\hline & Magnets \\
\hline $2 \mu_{\mathrm{th}} \mathrm{p}$ & \multirow{2}{*}{ None } \\
\hline \multirow[t]{2}{*}{$\left(\mu_{1} \pm \mu_{\mathrm{th}}\right) \mathrm{p}$} & \\
\hline & Armature \\
\hline $2 v_{\text {th }}$ & $\mathrm{H}_{\mathrm{v}} 1$ \\
\hline \multirow[t]{3}{*}{$\left(v_{1} \pm v_{\text {th }}\right)$} & $\mathrm{H}_{\mathrm{v}} 5, \mathrm{H}_{\mathrm{v}} 11, \mathrm{H}_{\mathrm{v}} 17, \mathrm{H}_{\mathrm{v}} 23, \ldots$ \\
\hline & Interaction effect : \\
\hline & Magnets-Permeance \\
\hline $2\left(\mu_{\mathrm{th}} \mathrm{p} \pm \mu_{\mathrm{th}} \mathrm{Z}_{\mathrm{s}}\right)$ & \multirow{2}{*}{ None } \\
\hline$\left(\mu_{\mathrm{th}} \pm \mu_{\mathrm{th}}\right) \mathrm{p} \pm\left(\xi_{2} \pm \xi_{1}\right) \mathrm{Z}_{\mathrm{s}}$ & \\
\hline \multirow[t]{2}{*}{$\left(\mu_{\mathrm{th}} \pm \mu_{\mathrm{th}}\right) \cdot \mathrm{p} \pm \xi \cdot \mathrm{Z}_{\mathrm{s}}$} & $\mathrm{H}_{\mu} 1, \mathrm{H}_{\mu} 3 ; \mathrm{H}_{\xi} 1$ \\
\hline & Armature-Magnet \\
\hline \multirow[t]{2}{*}{$\left(\mu_{\text {th }} \cdot p\right) \pm v_{\text {th }}$} & $\left(\mathrm{H}_{\mu} 1\left({ }^{*} \mathrm{p}\right), \mathrm{H}_{\mathrm{v}} 7\right) ;\left(\mathrm{H}_{\mu} 3\left({ }^{*} \mathrm{p}\right), \mathrm{H}_{\mathrm{v}} 23\right)$ \\
\hline & Magnet- Permeance-Armature- \\
\hline $\begin{array}{c}\left(\mathrm{p} \cdot \mu_{\mathrm{th}}\right) \pm\left(\xi \cdot Z_{\mathrm{s}}\right) \pm v_{\mathrm{th}} \\
\xi=\{0,1,3, \ldots\}\end{array}$ & $\begin{array}{c}\mathrm{H}_{\mathrm{v}} 5, \mathrm{H}_{\mu} 3(\text { for } \xi=1) \\
\mathrm{H}_{\mathrm{v}} 17, \mathrm{H}_{\mu} 11(\text { for } \xi=3)\end{array}$ \\
\hline
\end{tabular}

The table also gives the details of the second group of harmonics given by $\mathrm{H}_{\mathrm{v}} 1$ (first harmonic armature effect) and $\mathrm{H}_{\mathrm{v}} 5, \mathrm{H}_{\mathrm{v}} 11$, linked to specific harmonics $\mathrm{v}=6 \mathrm{k} \pm 1$ with $\mathrm{k}=\{0,1,2,3 .$.$\} called stator slots harmonics [3], [7].$

The third group of interactions involving permeance and rotor and stator magnetomotive forces harmonics is also responsible for the generation of order 2. Harmonics $\mathrm{H}_{\mathrm{v}} 1$ and $\mathrm{H}_{\mu} 1, \mathrm{H}_{\xi} 1$, are related to the armature and interactions due to the magnet- slotting permeance, and $\mathrm{H}_{v} 5, \mathrm{H}_{\mu} 3, \mathrm{H}_{\mathrm{v}} 17, \mathrm{H}_{\mu} 11$ are related to the magnetpermeance-armature considering respectively $\xi=1$ and $\xi=3$, respectively, as permeance harmonics.

The interaction of armature and magnet effects generates $\left.\mathrm{H}_{\mu} 1{ }^{*} \mathrm{p}\right), \mathrm{H}_{\mathrm{v}} 7$, and $\mathrm{H}_{\mu} 3(* \mathrm{p}), \mathrm{H}_{\mathrm{v}} 17$. Considering the number of pole pairs $\mathrm{p}$ (see Table 2) the armaturemagnet interaction $\mathrm{H}_{\mu} 1$ is equal to $\mathrm{H}_{\mu} 5$ which represents the number of pairs of poles. Following the same reasoning the harmonic $\mathrm{H}_{\mu} 3$ is equal to $\mathrm{H}_{\mu} 15$.

Additionally, the ACHFO tool determines the space orders and frequencies of the radial flux density as detailed in Table 3. Figure 6 illustrates the radial flux density 2D FFT obtained from the FE electromagnetic model. It validates the previous analytical flux density results. These results can be used for the second approach with the convolution product.
TABLE 3: ANALYTICAL ORDERS FLUX DENSITY RESULTS

\begin{tabular}{|c|c|}
\hline & Flux density $\mathrm{H}_{\mathrm{B} \mu, \mathrm{v}}$ Orders at $\mu_{\mathrm{th}} \mathrm{fs}$ \\
\hline & Magnets \\
\hline \multirow{2}{*}{$\left(\mathrm{H}_{\mathrm{B} \mu} ; \mathrm{f}\right)=\left(\mu_{\mathrm{th}} * \mathrm{p} ; \mu_{\mathrm{th}} \mathrm{fs}\right)$} & $\left(\mathrm{H}_{\mathrm{B} \mu}-5 ; \mathrm{fs}\right)$ and $\left(\mathrm{H}_{\mathrm{B} \mu}-15 ; 3 \mathrm{fs}\right)$ \\
\hline & Armature \\
\hline \multirow[t]{2}{*}{$\left(\mathrm{H}_{\mathrm{Bv}} ; \mathrm{f}\right)=\left(2 \mathrm{v}_{\mathrm{th}}-1 ; \mathrm{fs}\right)$} & $\left(\mathrm{H}_{\mathrm{Bv}} 1 ;\right.$ fs $)$ and $\left(\mathrm{H}_{\mathrm{Bv}} 9 ;\right.$ fs $)$, \\
\hline & Interaction Magnets -Permeance \\
\hline$\left(\mathrm{H}_{\mathrm{B} \mu \xi} ; \mathrm{f}\right)=\left(\xi \mathrm{Z}_{\mathrm{s}} \pm \mu_{\mathrm{th}} \mathrm{p} ; \mu_{\mathrm{th}} \mathrm{fs}\right)$ & $\begin{array}{c}\left(\mathbf{H}_{\mathrm{B} \mu \xi}-3 ; 3 f s\right),\left(\mathbf{H}_{\mathrm{B} \mu \xi} 7 ; \mathbf{f s}\right) \\
\left.\left(\mathrm{H}_{\mathrm{B} \mu \xi}-17 ; \mathrm{fs}\right),\left(\mathrm{H}_{\mathrm{B} \mu \xi} 19 ; \mathrm{fs}\right),\left(\mathrm{H}_{\mathrm{B} \mu \xi}\right) ; 3 \mathrm{fs}\right), \ldots\end{array}$ \\
\hline
\end{tabular}



Fig.6: Air-gap radial flux density 2D-FFT

\section{B. Convolution product.}

In order to compare our ACHFO results (Table 1 and 2 ), we use another approach: the convolution approach. This approach as given in [14], is based on the twodimensional Direct Fourier Transform (2D-DFT) of the air-gap radial flux density and its convolution with itself (10). This approach considers the radial flux density from FE simulation and is characterized by considerable simulation and computing time when taking into accounts all the orders. However, this approach offers the possibility of determining the amplitude and the phase of the radial pressure for each low order and justifies the order 2 progressive wave of mechanical deformation, as shown in the experimental part (figure $11 \mathrm{a}-\mathrm{d})$.

$\sigma_{2 D F T}(r, f)=1 / 2 \mu_{0} *\left[B_{2 D-D F T}\left(k_{1}, f_{1}\right) * B_{2 D-D F T}\left(k_{2}, f_{2}\right)\right]$

$r$ : Space order radial pressure by convolution approach.

Figure 7 represents the radial pressure space orders and frequency obtained by the convolution methodology. The air-gap flux density is calculated by the finite element method for the studied modular machine and we obtain the same results as in figure 5 . 


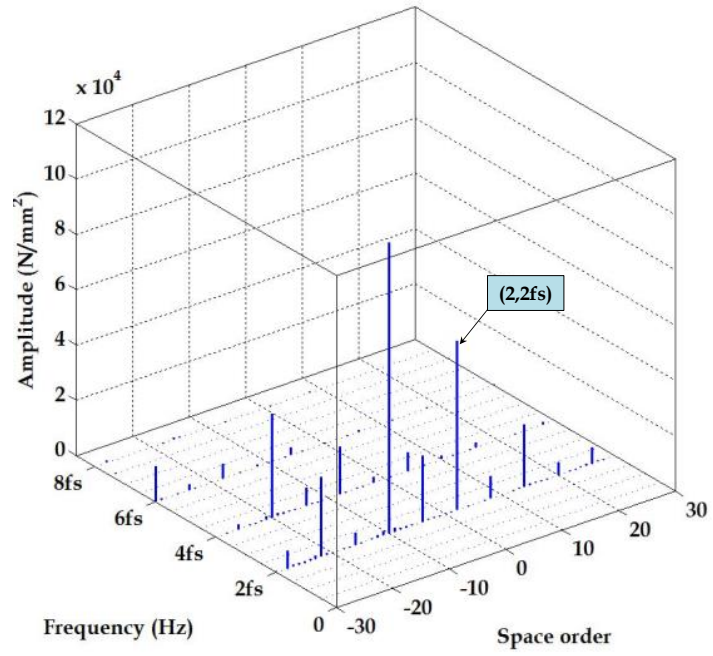

Fig.7: Air-gap radial pressure using convolution approach

It shows the order 2 at $2 \mathrm{fs}$. We consider thirty harmonics versus time and space. The amplitudes of each harmonics are the same for the spectrum obtained by FE simulations.

Considering a small set of around 10 space orders, figure 8 shows lows space orders and frequencies.

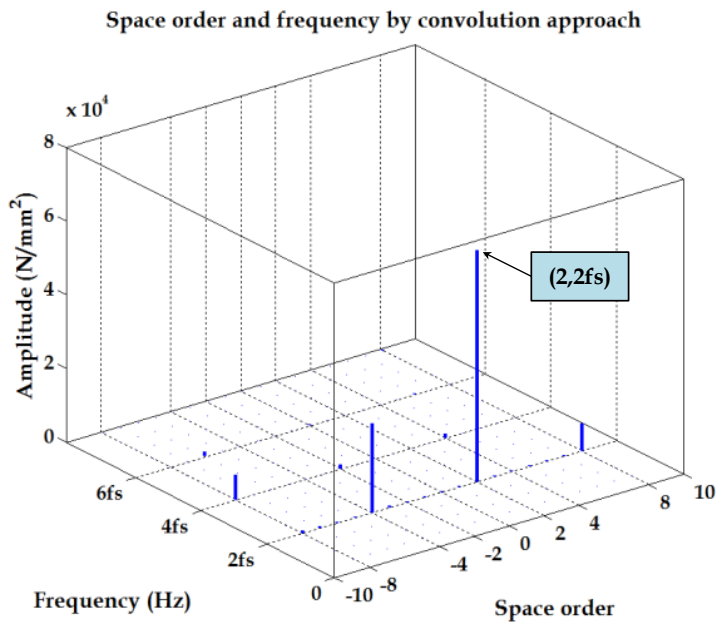

Fig.8: Lows space order by convolution approach ( $\mathrm{B}_{\mathrm{aG}}$ product)

The results of the convolution approach produce the phase and the amplitude of order 2 at $2 \mathrm{f}_{\mathrm{s}}$ of the air-gap radial pressure from the 2D-FFT radial flux density, table 4 .

All the harmonics and the frequencies at the origin of the order 2 can be found. Principally $\mathrm{H}_{\mathrm{B} \mu} 5$ and $\mathrm{H}_{\mathrm{B} \mu \xi} 7$ with high amplitude (multiplied by approximately 10 in comparison with other relevant harmonics) are identified by ACHFO as a magnet effect and the interaction between the magnet and permeance.
TABLE 4 ANALYTICAL CONVOLUTION RESULTS

\begin{tabular}{|c|c|c|c|c|c|c|c|c|}
\hline \multicolumn{3}{|c|}{ Order pressure } & \multicolumn{4}{|c|}{ Order flux density } & \multicolumn{2}{|c|}{ Radial pressure } \\
\hline $\mathrm{r}$ & $\mathrm{f}$ & $\mathrm{f} / \mathrm{fs}$ & $\mathrm{k}_{1}$ & $\mathrm{k}_{2}$ & $f_{1}$ & $f_{2}$ & \multirow{2}{*}{$\begin{array}{c}\mathrm{Amp} \\
\left(\mathrm{N} / \mathrm{mm}^{2}\right)\end{array}$} & \multirow{2}{*}{$\begin{array}{c}\text { Phase } \\
\left({ }^{\circ}\right)\end{array}$} \\
\hline \multirow{15}{*}{2} & \multirow{15}{*}{371} & \multirow{15}{*}{2} & \multicolumn{4}{|c|}{ Air gap Radial flux density } & & \\
\hline & & & 1 & 1 & fs & fs & 1505.33 & -32.60 \\
\hline & & & -3 & 5 & $3 \mathrm{fs}$ & fs & 3637.88 & 52.36 \\
\hline & & & -5 & 7 & $f s$ & $f s$ & 31790.37 & 1.06 \\
\hline & & & -15 & 17 & $3 \mathrm{fs}$ & fs & 3198.91 & 49.08 \\
\hline & & & -17 & 19 & fs & fs & 1849.00 & 54.93 \\
\hline & & & \multicolumn{4}{|c|}{ Magnet Radial flux density } & \multicolumn{2}{|c|}{ Radial pressure } \\
\hline & & & -3 & 5 & $3 \mathrm{fs}$ & fs & 3401.43 & 39.25 \\
\hline & & & -5 & 7 & $f s$ & fs & 14072.44 & -50.74 \\
\hline & & & -15 & 17 & $3 \mathrm{fs}$ & fs & 2832.96 & 39.26 \\
\hline & & & -17 & 19 & fs & fs & 1501.16 & 39.26 \\
\hline & & & \multicolumn{4}{|c|}{ Armature Radial flux density } & \multicolumn{2}{|c|}{ Radial pressure } \\
\hline & & & 1 & 1 & fs & fs & 1493.58 & -34.43 \\
\hline & & & -3 & 5 & $3 \mathrm{fs}$ & fs & 1234.37 & 39.76 \\
\hline & & & -5 & 7 & $f s$ & $f s$ & 13591.58 & 52.99 \\
\hline
\end{tabular}

The space vector diagram is shown in figure 9 where all the radial pressure vectors harmonics appear (grey box: Table 4). These main harmonics are at the origin of radial force order 2 at $2 \mathrm{fs}$ in the air gap.

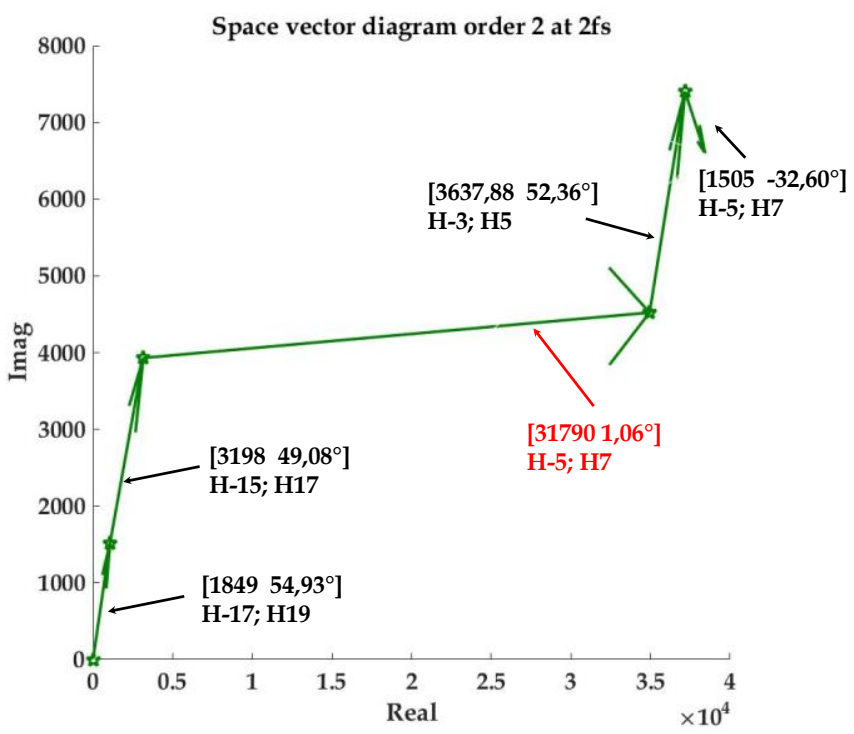

Fig.9: Space vector diagram.

Note that the real value represents the radial pressure in $\left(\mathrm{N} / \mathrm{mm}^{2}\right)$.

Taking into account the sign of these harmonics, we confirm that they are at the origin of the order 2 vibration progressive wave linked to the rotation field harmonics (Figure 11 a-d).

\section{EXPERIMENT RESULTS}

In order to validate the simulation results obtained by the radial pressure of the electromagnetic model an Operational Deflection Shape (ODS) was carried out with the Pulse LabShop software. The aim was to obtain the spatial deformation of the stator yoke for a given frequency. This was done by running several vibration measurements along the stator circumference: 10 points considered. Radial vibrations are recorded with the aid of four accelerometers, besides a reference accelerometer. 
These three accelerometers (1,2 and 3: figure 10) are sequentially displaced on the mesh defined for the operational deflection shape. Data acquisition and postprocessing are done in Pulse Labshop software.

The machine was run at constant rotation speed $\left(\mathrm{N}_{\mathrm{s}}=\mathrm{f}_{\mathrm{s}} / \mathrm{p}\right)$ under load $\mathrm{I}=4 \mathrm{~A}$ ( $25 \%$ rated current $)$.

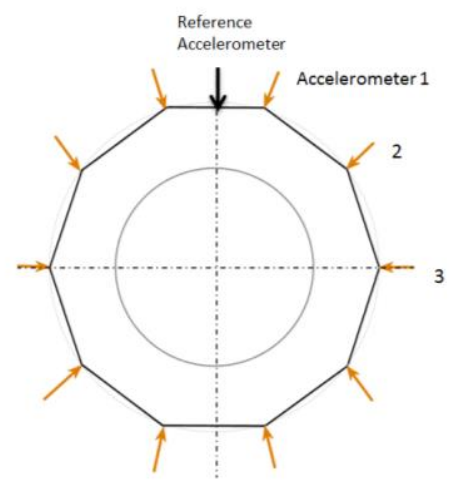

Fig.10: ODS trials (accelerometers positions)

The goal was to validate the pressure line of order 2 at $2 \mathrm{f}_{\mathrm{s}}$ observed in the FE results. Figure 11 a-d presents the deflection shape observed at different times. A mechanical deformation of order 2 can be seen (ovalization) at $2 \mathrm{f}_{\mathrm{s}}$.
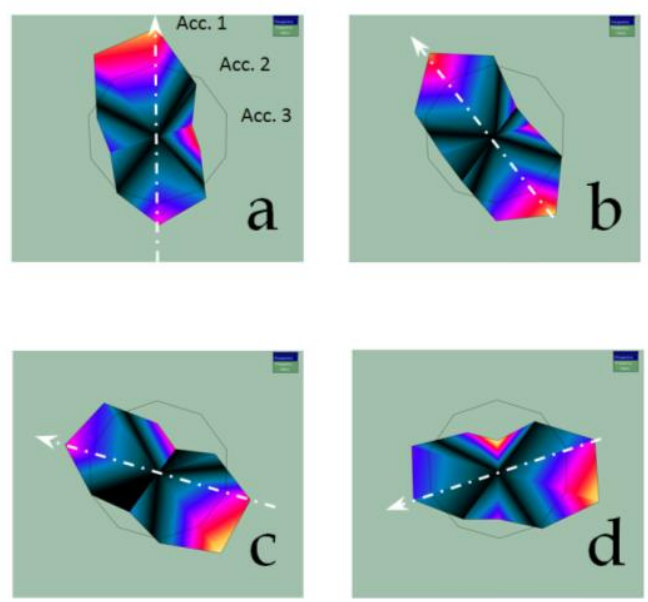

Fig.11: Vibration wave-Mode 2-2fs

It appears that this vibration wave of order 2 is a progressive rotating wave whose origins have been described by ACHFO and the convolution approach link to the rotating wave of the flux density ( $\mathrm{H} 5$ and $\mathrm{H} 7$ ).

Another approach to visualize, identify and quantify the vibrations of an electrical machine under air-gap radial pressure is called "spatiogram" [21]. This approach is based on the spectrogram visualization of the vibration waves filtered by wavenumbers and we have obtained the same result about this order 2 .

\section{CONCLUSION}

Several methods of simulation was presented, which calculates the Maxwell air-gap pressure acting in PMSM which is responsible for magnetic vibration and acoustic noise. An analytical ACHFO tool was therefore applied to investigate the origin of this radial pressure wave. It was found that many interactions are involved in this generation, involving both no-load and load-related harmonics.

Different approaches were proposed and compared with experimental measurements to identify the origin of the low space order. A rotating pressure wave of spatial order 2 (ovalization) was identified at twice the fundamental frequency as the most harmful wave in terms of vibration.

These investigations showed that the low orders 2 are generated principally by $\mathrm{H}_{\mathrm{B} \mu} 5$ and $\mathrm{H}_{\mathrm{B} \mu \xi} 7$, the magnet effect and the interaction between the magnet and permeance (see table 3) and own armature harmonics interaction $\mathrm{H}_{\mathrm{v}} 5-\mathrm{H}_{\mathrm{v}} 7$ as shown in table 2 .

A comparison with the convolution approach was finally established to validate the analytical tool. The latter approach, which requires numerical simulations to know the induction distribution in the air-gap, confirmed the analytical calculation.

Finally, experimental vibration measurements were carried out. The tests showed that the main radial pressure harmonic frequency and spatial order was correctly analysed with ACHFO and with the convolution approach.

\section{REFERENCES}

[1] P. L. Timár, Noise and Vibration of Electrical Machines, vol. 34. Amsterdam, The Netherlands: North Holland, Sep. 1989.

[2] J.F. Gieras, C. Wang, and J. Cho Lai, "Noise of Polyphase Electric Motors", CRC, Press, Taylor Francis Group, 2005.

[3] Huang S. , Aydin M. and Lipo T.A, «Electromagnetic Vibration and Noise Assessement for Surface Mounted PM Machines », , Power Engieneering Society Summer Meeting, July 2001, vol 3, pp : 1417 1426 .

[4] J. Le Besnerais, V. Lanfranchi, M. Hecquet, G. Lemaire, E. Augis, and P. Brochet, «Characterization and reduction of magnetic noise due to saturation in induction machines", Magnetics, IEEE Transactions on, Vol. 45, Issue: 4, April 2009.

[5] J. Le Besnerais, V. Lanfranchi, M. Hecquet, P. Brochet, "Characterization and Reduction of Audible Magnetic Noise Due to PWM Supply in Induction Machines, Industrial Electronics, IEEE Transactions on, Vol. 57, Issue: 4 , August 2009.

[6] J. P. Lecointe, B. Cassoret, and J. F. Brudny, "Distinction of toothing and saturation effects on magnetic noise of induction motors", Progress In Electromagnetics Research, Vol. 112, 125-137, 2011.

[7] Z. Q. Zhu, Z.P. Xia, L. J. Wu, G.W. Jewell, "Analytical Modelling and Finite Element Computation of Radial Vibration Force in FractionalSlot, Industry Applications, IEEE Transactions on, Vol. 46, Issue: 5, July 2010.

[8] Zhu, Z.Q. Xia, Z.P.; Wu, L.J.; Jewell, G.W. "Influence of slot and pole number combination on radial force and vibration modes in fractional slot PM brushless machines having single- and double-layer windings", Energy Conversion Congress and Exposition, 2009, ECCE 2009, IEEE.

[9] Z. Q. Zhu, L. J. Wu, and Z. P. Xia, "An Accurate Subdomain Model for Magnetic Field Computation in Slotted Surface-Mounted PermanentMagnet Machines," IEEE Transactions on Magnetics, vol. 46, no. 4, pp. 1100-1115, 2010. 
[10] P. La Delfa, M. Hecquet, and F. Gillon, "Harmonics Analysis Tool of Radial Force for Permanent Magnet Synchronous Machine," ISEF Conference, ISEF 2013 - XVI International Symposium on Electromagnetic Fields in Mechatronics, Electrical and Electronic Engineering, pp. 2-7, 2013.

[11] J.Le Besnerais, "Vibro Acoustic Analysis of radial and Tangential Airgap Magnetic Pressures in permanent Synchronous Machines” IEEE Trans on Magnetics, Vol. 51, $\mathrm{N}^{\circ}$. 6, June 2015.

[12] R.Islam,I.Hussain, « Analytical model for predicting noise and vibration in Permanent magnet synchronous motors », Industry Applications, IEEE Transactions on, Vol 46, N6, November 2010.

[13] M. S. Islam, R. Islam and T. Sebastian, "Noise and Vibration Characteristics of Permanent-Magnet Synchronous Motors Using Electromagnetic and Structural Analyses," in IEEE Transactions on Industry Applications, vol. 50, no. 5, pp. 3214-3222, Sept.-Oct. 2014.

[14] M. Van Der Giet, R. Rothe, M. Garcia, K. Hameyer « A novel approach to estimate harmonic force excitation for noise diagnosis of electrical machines », ICS Newsletter vol 16, No 1, RWTH Aachen University, Schinkelstrasse 4, D-52056, Germany, Mars 2009.

[15] J.Soulard, F Libert, «Investigation on Pole-Slot Combination for Permanent Magnet Machines with Concentrated Windings », ICEM 04 5-8 september 2004, Cracow, Poland.
[16] B. Aslan, E. Semail, J. Korecki, J. Legranger, "Slot/pole Combinations Choice for Concentrated Multiphase Machines dedicated to Mild-Hybrid Applications", IECON'11 - 37th Annual Conference on IEEE Industrial Electronics Society, pp3698 - 3703, 7-10 Nov 2011, Melbourne.

[17] A.M El-Refaie, «Fractional slot concentrated- windings synchronous permanent magnet machines: Opportunities and challenge » IEEE Transaction on Industrial Electronics, Vol 57, N ${ }^{\circ}$, January 2010.

[18] P Viarouge, J Cros, «Synthesis of high performance PM Motors with concentrated windings», IEEE transaction on energy conversion, Vol 2 June 2002.

[19] H. Dogan, F. Wurtz, A. Foggia and L. Garbuio, "Performance analysis of windings configuration on fractional-slots PMSM performance," Power Electronics and Applications (EPE), 2013 15th European Conference on, Lille, 2013, pp. 1-7.

[20] M.Fakam, M.Hecquet,V.Lafranchi, A.Randria «Design and magnetic reduction of the surface Permanent Magnet Synchronous Machine" . IEEE Transaction On Magnetics, Vol. 51, N. 4, 04/2015.

[21] Quentin SOURON, Jean LE BESNERAIS, Michel HECQUET, "Analysis of electromagnetically-induced vibrations of electrical machines based on spatiogram technique", International Journal of Applied Electromagnetics and Mechanics (IJAEM), Vol. 51, N. S1, pages. S23 - S32, 04/2016 